\title{
Staining of urinary leucocytes as an aid to the diagnosis of inflammation in the urinary tract
}

\author{
D. M. HARRIS \\ From the Department of Bacteriology, The Royal Hospital, Sheffield
}

SYNOPSIS Five hundred specimens of urine have been examined for pyuria and bacteriuria, the leucocytes being stained by the Sternheimer-Malbin method. Most urines contained either less than ${ }_{*}^{N}$ 1 or more than 10 leucocytes per $\mathrm{cmm}$; a few specimens contained 1 to 10 cells per $\mathrm{cmm}$, whatever their viable bacterial count. The presence of leucocytes in urine was usually related to the bacteriali count, pyuria being commonest in urines showing 'significant bacteriuria'. However, urinary tract? instrumentation caused pyuria in the absence of infection. Leucocytes with nuclei staining blue by the Sternheimer-Malbin technique were considered to be indicative of active inflammation, but $\subseteq$ the incidence of such cells appeared to be a reflection of the total leucocyte count of the specimenrather than of its viable bacterial count. In the majority of cases the diagnosis of infection can beo made on the basis of the bacterial count and the degree of pyuria. The staining technique appears. to have a limited use, restricted to the interpretation of cases in which the results of culture ando conventional leucocyte counts are ambiguous.

In a clinical bacteriology department, pathologists are frequently confronted with the problem of assessing the significance of pyuria and bacteriuria. The definition by Kass (1956) of a level of 'significant bacteriuria' has done much to clarify the differentiation of infection from contamination, and some form of quantitative or semi-quantitative culture is now standard practice in most laboratories. Nevertheless, in a proportion of patients, the 'significant' level of $10^{5}$ organisms per millilitre of urine will not be observed, despite the presence of active infection, since such factors as frequency of micturition or diuresis may prevent the multiplication of bacteria in the bladder which is necessary for attainment of the significant level (Roberts, Robinson, and Beard, 1967). In hospital bacteriology, the situation is further complicated by the fact that many patients may be receiving antibacterial therapy, and the drugs may reach such high concentrations in the urine that bacterial growth on culture media is inhibited. Indeed certain authors (Wear, 1966; Bradley, Crowley, and Darrell, 1967) question the wisdom of too rigid an adherence to the criterion of $10^{5}$ organisms per millilitre in the interpretation of urine cultures.

Received for publication 14 November 1968.
In these circumstances, when one cannot alto- 3 gether rely on the results of quantitative culture, it? is frequently necessary to seek supportive evidenceo of infection in the form of pyuria. However, the situation with regard to leucocyte counts is in some? respects even less satisfactory. There is no unanimity in the method of expressing results, some workers examining the centrifuged deposit and counting the number of cells 'per high-power field', others counting the number of leucocytes per cubic millimetre of 5 uncentrifuged urine in a counting chamber. Further $\frac{7}{0}$ more the advocates of each method differ amongthemselves as to the number of leucocytes which or they are prepared to accept as a normal level, $n$ although Stansfeld and Webb (1953) and Little (1964) have produced evidence to support a figure $\omega$ of 10 leucocytes per $\mathrm{cmm}$ as the upper limit of normality. However, there has been a generaf? tendency to regard pyuria as a relatively imprecise aid to the diagnosis of urinary tract infections (see Brumfitt, 1965), and this may be due to the fact that authors commenting on centrifuged deposits have not standardized their methods. However, Berman and Chappelle (1963) suggested that in their experience a consistent finding of 1 pus cell per high $-\frac{}{2}$ power field of centrifuged urine was abnormal. 
It is the aim of the present study to explore the usefulness of qualitative changes in the urinary leucocytes as a diagnostic guide to the presence of significant inflammation in the urinary tract; the method used detects differing degrees of viability of leucocytes, employing the staining technique of Sternheimer and Malbin (1949). Previous experience with this stain in the investigation of experimental pyelonephritis of mice (Harris, 1968a) suggested that pale, blue-staining nuclei in urinary leucocytes were indicative of active inflammation, while in chronic and resolving infections the nuclei of pus cells were found to stain dark reddish-purple. This difference was found to hold good both in infections caused by Gram-negative bacilli (Harris, 1968a) and in those caused by Gram-positive cocci (Harris, 1968b), and secondary infection was accompanied by an increase in the number of leucocytes showing blue staining of the nuclei (Harris, 1968c). The stain has now been used on 500 urine specimens in a hospital clinical laboratory.

\section{MATERIALS AND METHODS}

The urines studied were mostly clean-voided midstream specimens, except in those cases where catheterization had been necessary for some other reason. In order that the study should represent conditions encountered in normal bacteriological practice, the specimens were selected from those submitted for routine examination. However, specimens falling into any of the following categories were excluded: (1) those in which the time interval between collection and examination exceeded one and a half hours; (2) those submitted from patients with known or suspected genito-urinary tuberculosis; (3) those with macroscopic haematuria; (4) those found to contain large numbers of squamous epithelial cells.

Specimens were examined as soon as possible after receipt, and always within one hour. Apart from adherence to the criteria cited above, urines were selected at random and there was no conscious bias in favour of the inclusion of urines from any particular source. However, since this hospital has an active urological department, many of the urines happened to come from patients with disease of the urinary tract.
Viable bactelial counts were performed in triplicate by a nutrient agar pour-plate technique, employing tenfold dilutions of uncentrifuged urine. Organisms were identified from parallel cultures made with a standard loop on blood agar and MacConkey agar. During analysis, viable counts were considered in three categories: (1) fewer than $10^{4}$ organisms per millilitre; (2) more than $10^{4}$ but less than $10^{5}$ organisms per millilitre; (3) $10^{5}$ or more organisms per millilitre. Cultures showing a mixed flora of two or more bacterial species were classified according to the viable count of the predominant species.

Leucocyte counts were performed on uncentrifuged urine in a Fuchs-Rosenthal counting chamber after adding an equal volume of Sternheimer-Malbin stain to the urine. The number of leucocytes per cubic millimetre and the percentage of cells with blue-staining nuclei were recorded, No differentiation was made between the 'glittering' and 'non-glittering' forms of the latter (Harris, 1968a). Total leucocyte counts were considered in three categories: less than 1 cell per $\mathrm{cmm}, 1$ to 10 cells per $\mathrm{cmm}$, and more than 10 cells per $\mathrm{cmm}$.

Sternheimer-Malbin stain was prepared according to the directions of its originators (Sternheimer and Malbin, 1949).

\section{RESULTS}

From Table I it can be seen that the percentage of urines found to contain leucocytes was related to the bacterial count of the specimens. Thus only $37.3 \%$ of urines in group 1 showed evidence of pyuria (and only $23 \%$ contained more than 10 leucocytes per $\mathrm{cmm}$ ), while in group $383.9 \%$ of urines contained leucocytes, and in $76.4 \%$ these were present in numbers greater than 10 per $\mathrm{cmm}$.

The incidence of pyuria was significantly higher in group 2 than in group 1 , and significantly higher in group 3 than in group $2(P<0.001)$. For any given viable bacterial count, relatively few urines contained between 1 and 10 cells per cmm.

Analysis of the histories of the patients represented by the urines in group 1 showed that 92 of the 128 patients with pyuria were known to be suffering from a primary disease of the urinary

THE INCIDENCE OF PYURIA AND ITS RELATION TO VIABLE BACTERIAL COUNT AND PERCENTAGE OF LEUCOCYTES SHOWING BLUE STAINING OF THE NUCLEI

Viable Bacterial Count (organisms per $\mathrm{ml}$ )

\begin{tabular}{lll}
\hline Group 1 & Group 2 & Group 3 \\
$\left(<10^{4}\right)$ & $\left(10^{4}-10^{5}\right)$ & $\left(10^{5}\right.$ or more $)$
\end{tabular}

Total number of urines

Number with leucocyte counts of:

$<1$ cell per $\mathrm{cmm}$

1-10 cells per $\mathrm{cmm}$

$>10$ cells per $\mathrm{cmm}$

Total number of urines with pyuria

Number of urines with pyuria showing blue staining

of leucocyte nuclei
343

64

$215(62 \cdot 7 \%)$

$49(14.3 \%)$

$79(23.0 \%)$

$128(37 \cdot 3 \%)$

$75(58.6 \%)$
93

$26(40.6 \%)$
$8(12.5 \%)$
$30(47.9 \%)$
$38(59.4 \%)$

$29(76.3 \%)$
$15(16.1 \%)$

$7(7.5 \%)$

$78(83.9 \%)$

$67(85.9 \%)$ 


\begin{tabular}{|c|c|c|c|}
\hline \multirow{2}{*}{$\begin{array}{l}\text { Urinary Leucocyte } \\
\text { Count } \\
\text { (cells per cmm) }\end{array}$} & \multicolumn{2}{|c|}{ No. of Urines } & \multirow{2}{*}{$\begin{array}{l}\text { Mean Percentage of } \\
\text { Leucocyte Nuclei } \\
\text { Staining Blue }\end{array}$} \\
\hline & Total & $\begin{array}{l}\text { With Blue-staining } \\
\text { Leucocytes }\end{array}$ & \\
\hline $\begin{array}{l}1-10 \\
>10\end{array}$ & $\begin{array}{r}64 \\
180\end{array}$ & $\begin{array}{r}34(53.1 \%) \\
162(90.0 \%)\end{array}$ & $\begin{array}{l}36 \cdot 9 \\
59 \cdot 2\end{array}$ \\
\hline
\end{tabular}

tract, eg, prostatic hypertrophy, renal or bladder calculi, urethral stricture, etc, and 64 of them had undergone some form of instrumentation. The majority had not received antibacterial therapy. A further nine specimens were derived from women who had presented with symptoms of frequency and dysuria, possibly examples of the so-called 'urethral syndrome' rather than of cystitis in the conventional sense.

An attempt was also made to discover a common factor among the 15 patients in group 3 whose urine contained less than 1 leucocyte per $\mathrm{cmm}$. Three of the patients had symptoms suggestive of acute infection, and there was no obvious explanation for the absence of pyuria; in the remainder, infection was known to be chronic and presumably the original acute inflammatory manifestations had long disappeared.

Table I also shows that the percentage of cells showing blue staining of the nuclei appeared to increase in accordance with the viable bacterial count. The difference between groups 1 and 2 in this respect achieves statistical significance $(\mathrm{P}<$ 0.01 ), but the difference between groups 2 and 3 is not significant.

In order to assess the usefulness of the staining technique in the interpretation of 'doubtful' viable bacterial counts, further attention was paid to that group of 38 urines, represented in Table I, which showed pyuria but contained between $10^{4}$ and $10^{5}$ organisms per millilitre, $i e$, they did not reach the conventional level of 'significant bacteriuria'. Further information was available on 22 of the patients. In five of these the specimen included in the study had contained dark-staining leucocytes only; the remaining 17 had contained varying proportions of blue-staining cells. Follow-up cultures were performed in 16 of these cases, and the presence of a true urinary infection was subsequently confirmed in all. In each case, the total leucocyte count of the specimen included in the study had been considerably greater than 10 cells per $\mathrm{cmm}$.

Of the five patients excreting darkly stained cells only, it was found that only one could subsequently be shown to have a true urinary tract infection when further cultures were performed. (It is of interest to note that this patient was the only one of the five to have a urinary leucocyte count of more than 1 cells per $\mathrm{cmm}$.)

These results suggest that the excretion of leuco $\vec{\omega}$ cytes with blue-staining nuclei is more closelyo related to the while-cell excretion rate than to the bacterial count of the specimen. In Table II thei percentage of urines found to contain blue-staining $\mathrm{s}_{\triangle}$ leucocytes is related to the total leucocyte countsi of the specimens, irrespective of the viable bacterial counts. It can be seen that there is a striking differ윽 ence between the groups containing 1 to 10 leucocytes per $\mathrm{cmm}$ and more than 10 leucocytes pere $\mathrm{cmm}$, respectively $(\mathrm{P}<0.001)$. There is a significant difference also in the mean percentage of $\overrightarrow{0}$ urinary leucocytes found to show blue staining ofe the nuclei in the two groups $(\mathrm{P}<0.001)$.

\section{DISCUSSION}

The results obtained support the inference already made from studies on experimental pyelonephritis $\rightarrow$ (Harris, 1968a, b, c) that the excretion of leucocytes의 with blue-staining nuclei is indicative of acute inflammation in the urinary tract. However, as Brumfitt (1965) has pointed out, evidence of inflam mation is not necessarily proof of bacterial infection.? The fact that the presence of such cells is a reflection of a raised white-cell excretion rate implies that the cells may be seen in some of the conditions of nonbacterial origin (De Wardener, 1960) which give rise to a raised excretion rate. In the present investi-은 gation it was apparent that patients who had under gone instrumentation of the urinary tract sometimes showed pyuria, including blue-staining leucocytes, N even though the viable bacterial count was less than $10^{4}$ organisms per millilitre. It is interesting to find that, irrespective of the bacterial count, few speci- $\omega$ mens of urine contain 1 to 10 leucocytes per cmm? When urine is centrifuged at $3,000 \mathrm{rpm}$ for five minutes (as is the normal practice in many labor- $-\mathbb{D}$ atories) the deposit from specimens containing $10^{-}$ cells per $\mathrm{cmm}$ is usually found on resuspension to $\frac{T}{\circ}$ reveal approximately one white cell per high-power field. This tends to support the contention of Berman and Chappelle (1963) that a finding of oneo leucocyte per high-power field is abnormal.

It is apparent from the results obtained that in 
the majority of clinical specimens, a diagnosis of infection can readily be made from a consideration of the viable bacterial count and the degree of pyuria alone. Even in cases where the bacterial count lies between $10^{4}$ and $10^{5}$ organisms per millilitre, the presence in the urine of 10 or more leucocytes per $\mathrm{cmm}$ suggests probable infection. It is in these cases that the differential staining technique should have its greatest value. However, the fact that the percentage of blue-staining cells seen is related to the total white cell count rather than to the bacterial count limits its usefulness in this respect. But in the present study, when the percentage of cells with bluestaining nuclei in a specimen exceeded $50 \%$, subsequent specimens tended to confirm the presence of active infection. If, however, the doubt can usually be resolved by repeating the cultures, the main advantage of using the staining technique is seen to be one of saving time only; in other words, it may be possible to take decisions concerning treatment without the delay consequent upon the obtaining of further specimens.

It is no longer possible to support the original contention of Sternheimer and Malbin $(1949,1951)$ that blue staining of leucocyte nuclei is indicative of pyelonephritis rather than lower urinary tract inflammation, since Berman, Schreiner, and Feys (1956) found such cells in a variety of conditions, and Poirier and Jackson (1957) demonstrated that the blue staining was a reflection of the vitality of the nucleus rather than of damage caused by the pathological process of pyelonephritis. However, the staining reaction may be of value in assessing the activity of the disease process in cases of chronic pyelonephritis, where less reliance can be placed on the results of bacterial cultures. In this respect the test is simpler to perform than the conventional white-cell excretion rate estimation. The essentially non-specific nature of the blue staining of leucocyte nuclei does of course raise certain problems, since leucocytes of sufficient vitality will show this reaction, whatever their source. Therefore it is still necessary that measures be taken to prevent contamination of urine specimens, eg, by vaginal discharges. It is also essential that specimens of urine be examined without delay in view of the transience of the differential staining reaction(Harris, 1968a). However, these precautions are equally necessary for accurate interpretation of the viable bacterial count or the white-cell excretion rate and do not constitute any additional limitation.

I am grateful to Dr J. Colquhoun for his encouragement and helpful criticism.

\section{REFERENCES}

Berman, L. B., and Chappelle, E. H. (1963). Amer. J. clin. Path., 40, 276.

-, Schreiner, G. E., and Feys, J. O. (1956). New Engl. J. Med., 255, 989.

Bradley, J. M., Crowley, N., and Darrell, J. H. (1967). Brit med. J., $4,649$.

Brumfitt, W. (1965). J. clin. Path., 18, 550.

De Wardener, H. E. (1960). In Recent Advances in Renal Disease, edited by M D. Milne, p. 157. Pitman, London.

Harris, D. M. (1968a). J. Path. Bact., 96, 77.

- (1968b). Brit. J. exp. Path., 49, 128.

- (1968c). J. Path. Bact., 96, 421.

Kass, E. H (1956). Trans. Assoc Amer. Phycns., 69, 56.

Lindsay, R. M., Lunan, B., McGeachie, J., and Linton, A. L. (1967). Brit. med. J., 3, 83.

Little, P. J. (1964). Brit. J. Urol., 36, 360

Poirier, K. P., and Jackson, G. G. (1957). Amer. J. Med., 23, 579.

Roberts. A. P., Robinson, R. E., and Beard, R. W. (1967). Brit. med. $J ., 1,400$.

Stansfield, J. M., and Webb, J. K. G. (1953). Arch. Dis. Child., 28, 386.

Sternheimer, R., and Malbin, B. I. (1949). Amer. Heart J., 37, 678

- - (1951). Amer. J. Med., 11, 312

Wear, J. B., Jr (1966). J. Urol. (Baltimore), 96, 808. 